\title{
Molecular basis of oral cancer - A case report \& literature review
}

\author{
Shaik Ali Hassan ${ }^{1 *}$, Sumit Bhateja ${ }^{2}$, Geetika Arora ${ }^{3}$, Tamanna Soni ${ }^{4}$, Neha Aggarwal ${ }^{5}$ \\ ${ }^{1}$ Dental Surgeon, ${ }^{2} \mathrm{HOD},{ }^{3}$ Reader, ${ }^{4,5}$ Senior Lecturer, ${ }^{2,4,5}$ Dept. of Oral Medicine \& Radiology, ${ }^{3}$ Dept. of Public Health Dentistry, \\ 1,2,4,5Manav Rachna Dental College, Faridabad, Haryana, ${ }^{3}$ Inderprastha Dental College, Sahibabad, Uttar Pradesh, India
}

\section{*Corresponding Author: Shaik Ali Hassan}

Email: alishaikhassan@gmail.com

\begin{abstract}
An ulcer is a break in continuity of epithelium of skin or mucous membrane. Oral Ulcers have a prevalence of $15-30 \%$ In this case it was seen that a ulcer was seen on left buccal mucosa which was first considered to be the ulcer due to cheek bite but later on after taking incisional biopsy it was conformed a squamous cell carcinoma. Patient denied any history of tobacco use but gives positive family history.
\end{abstract}

Keywords: Squamous cell carcinoma, Ulcer, Oral cancer, Oncogenes.

\section{Introduction}

Squamous cell carcinoma (SCC) represents from $90 \%$ to $95 \%$ of all malignant neoplasms of the oral cavity, being located mainly in the tongue, especially in the lateral posterior border. It generally seen in men of age above 50years, most of them have a history of high tobacco and alcohol consumption. ${ }^{1}$ SCC rarely occurs in the young, i.e., patients under the age of 40.The cause of oral squamous cell carcinoma is multifactorial. No single causative agent or factor (carcinogen) has been clearly defined, but both extrinsic and intrinsic factors are available. Extrinsicfactors include such external agents as tobacco smoke, alcohol, syphilis, and (for vermilion cancers only) sunlight. Intrinsic factors include systemic or generalized states, such as general malnutrition or iron-deficiencyanemia. Incidence of oral SCC in young age varies between $0.4 \%$ and $6.6 \% .^{2}$ Some authors ${ }^{2,3}$ argue that these substances, recognized as carcinogenic in older patients, may also be related to SCC etiology in younger ones. Others ${ }^{4,5}$ however, report that many of those patients never smoked or drank alcoholic beverages, but still, who has exposure to these agents will have induction of malignant transformation. Classical feature of the lesion is persistent ulceration with hardening and peripheral infiltration, either being associated with vegetations, red or whitish staining or not. Predominant location is a lateral border of the tongue and floor of mouth.

\section{Case Report}

A thirty-eight-year-old male patient, came to Department of oral medicine and radiology with the chief complaint of the intense pain associated the left cheek region, with a duration of 15-20 days. The patient was apparently well 15-20 days back then he started experiencing pain in the area of the left cheek region. Pain was dull in nature, non-radiating, intermittent, aggravates on the opening mouth and subsides on taking medication. Patient gives a history of diabetes since 7-8yearsand he is under medication for the same. Patient doesn't have any history of the tobacco usage. Patient gives a positive family history of cancer of oropharyngeal region of father \& grandfather who died of this illness.

On inspection solitary oval in shape ulcer of size $1 \times 1 \mathrm{~cm}$, seen on left buccal mucosa (Fig. 2), it has rolled out edges, floor of the ulcer is filled with the granulation tissue, there is no discharge from the ulcer, surrounding area is glossy, red and oedematous. On palpation ulcer was tender, margins were inflamed, there was marked induration on base of ulcer, there was no bleeding, surrounding mucosa was normal in appearance \& tender. Regional lymphadenopathy was present. A clinical diagnosis Malignant ulcer was formulated.

Incisional biopsy was performed and histopathology (Fig. 4) revealed a fibro cellular connective tissue stroma with sheets and islands of tumor cells exhibiting dysplastic features like nuclear and cellular pleomorphism, increased nuclear-cytoplasmic and presence of enamel pearls. The intervening connective tissue is made up of dense bundles of collagen fibres and fibroblasts and infiltration of chronic inflammatory cells chiefly lymphocytes and plasma cells. Blood vessels of vary size \& shape along with muscle fibers are also evident. The overlying epithelium is para keratinized and proliferating in nature which is indicative of moderately differentiated squamous cell carcinoma. Differential diagnosis like Traumatic ulcer, Tubercular ulcer, Systemic mycosis, Syphilis, Eosinophilic ulcer, wegners granulomatosis, malignant granuloma \& Minor salivary gland carcinomas were considered in this case. So finally after the incisional biopsy the lesion was conformed as moderately differentiated squamous cell carcinoma.

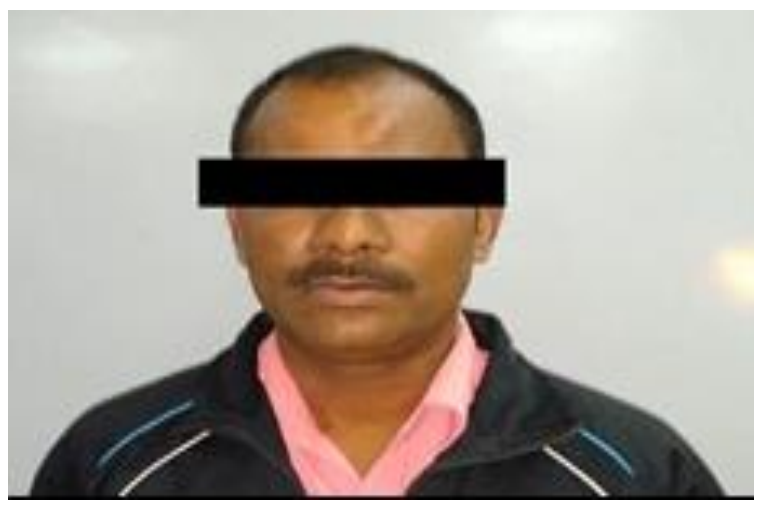

Fig.1: Extraoral photograph of patient 


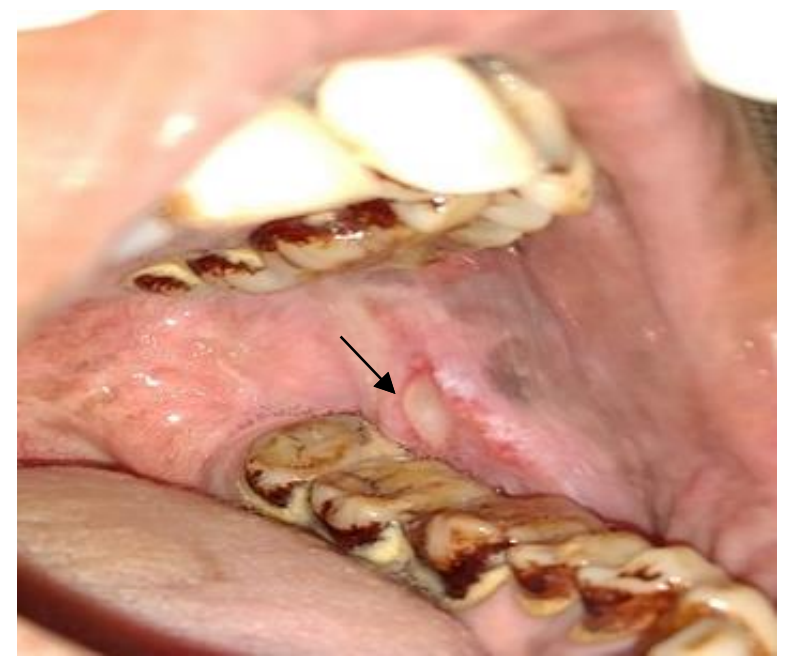

Fig. 2: Left buccal mucosa

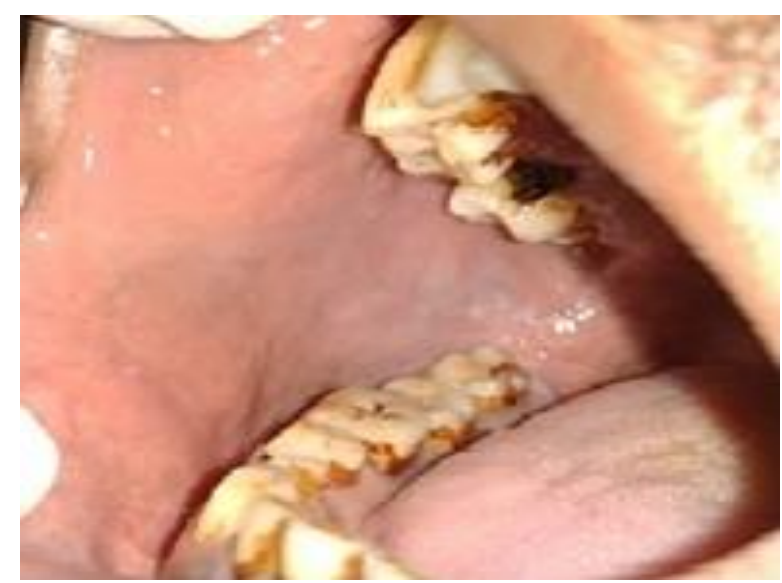

Fig. 3: Right buccal mucosa

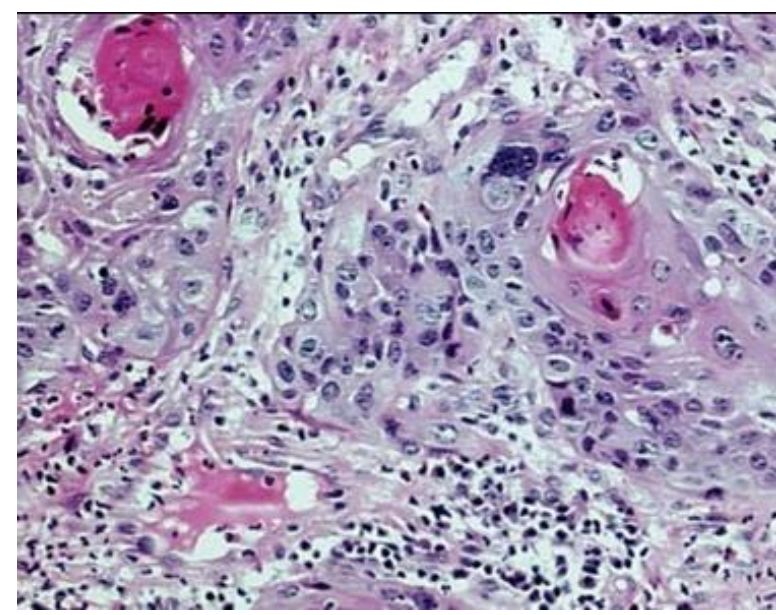

Fig. 4: Histopathology of moderately differentiated squamous cell carcinoma

\section{Discussion}

The incidence of oral cancer in young adults is uncommon before the age of 35 years. Even though tobacco and alcohol abuse are regarded as main aetiological factor. Buccal squamous cell carcinoma commonly occurs in people aged $50-80$.

In this above case the patient is $45 y$ years old came for compliant of an ulcer in left buccal mucosa. Then the examination of ulcer was done and was sent for biopsy of the ulcer. Biopsy revealed the presence of dysplastic features that included change in nuclear cytoplasmic ratio, presence of enamel pearls etc. The most common sites of metastases are the submaxillary lymph nodes. The incidence and prevalence of oral squamous cell carcinoma is increasing in the Indian subcontinent due to prevalent habits of chewing tobacco, betel quid and areca-nut. Buccal mucosa squamous cell carcinoma is the most common oral cancer in men and the third most common oral cancer in women in India, and accounts for one third of all tobacco-related cancers. This higher rate in India is related to the widespread practice of betel nut chewing, in addition to tobacco and alcohol (5). A betel nut quid typically consists of 3 ingredients: the areca nut, leaf of the betel pepper, and slaked lime paste obtained from shells, coral, or limestone. This combination of ingredients is more carcinogenic than betel nut used alone. Depending on their extent and/or location, these lesions may cause painful symptoms and resorption of adjacent bone seen as a "motheaten" appearance on radiographs. Genetic basis of mutation due to alcohol, tobacco and betel quid. Mutations occur in chromosome 3p, 4q, 6p, 8p, 9p, 11q, 13q, 14q, 18q, $17 q$. Oncogene encode for many signal transmuting proteins eg EGFr, Ra's, cytoplasmic kinase, which respond to external growth signals. Due to oncogene mutation, the mutant oncogene may send a growth stimulation to nucleus, regardless of events taking place in cells surroundings. The subsequent proliferation leads to mutant oncogene bearing cells resulting in tumor formation. ${ }^{6}$

Differential diagnosis includes Traumatic ulcer, Tubercular ulcer, Systemic mycosis, Syphilis, Eosinophilic ulcer, wegners granulomatosis, malignant granuloma \& Minor salivary gland carcinomas.

Treatment of OSCC generally requires the services of a multidisciplinary team, the main aim of treatment is to eradicate the cancer, to prevent recurrence and finally restore the form and function of the affected parts. Surgery is the preferred first line treatment of small, accessible OSCCs. However, advanced-stage OSCC is usually treated by a combined treatment program of surgery, chemotherapy, and radiotherapy. ${ }^{7}$

\section{Conclusion}

Ulcerative lesion in the oral cavity should raise the suspicion of serious issue as in this case of Squamous cell carcinoma of the buccal mucosa, there was also no tobacco and alcohol history, so the only causative factor here was genetic susceptibility which was evident through the history\& clinical examination.

\section{Source of funding}

None. 


\section{Conflict of interest}

None.

\section{References}

1. Friedlander PL, Schantz SP, Shaha AR, Yu G, Shah JP. Squamous cell carcinoma of the tongue in young patients: a matched-pair analysis. Head Neck 1998;20:363-8.

2. Sasaki T, Moles DR, Imai Y, Speight PM. Clinico-pathological features of squamous cell carcinoma of the oral cavity in patients <40 years of age. J Oral Pathol Med 2005;34:129-33.

3. Llewellyn CD, Johnson NW, Warnakulasuriya KAAS. Risk factors for squamous cell carcinoma of the oral cavity in young people - a comprehensive literature review. Oral Oncol 2001;37:401-18.

4. Oliver RJ, Dearing J, Hindle I. Oral Cancer in young adults: report of three cases and review of the literature. Br Dent J. 2000; $188: 362-5$.
5. Sankaranarayanan R, Najeeb Mohideen M, Krishnan Nair M, Padmanabhan TK. Aetiology of oral cancer inpatients < 30 years of age. Br J Cancer 1989;59:439-40.

6. R. Rajenderan and B. Sivapathasundharam, Shafer's Textbook of Oral Pathology, Elsevier, New York, NY, USA, 5th edition, 2006.

7. R. Rajenderan and B. Sivapathasundharam, Shafer's Textbook of Oral Pathology, Elsevier, New York, NY, USA, 5th edition, 2006

8. Schantz SP, Byers RM, Goepfert H, Shallenberger RC, Beddingfield $\mathrm{N}$. The implication of tobacco use in the young adult with head and neck cancer. Cancer 1988;62:1374-80.

How to cite this article: Hassan SA, Bhateja S, Arora G, Soni T, Aggarwal N. Molecular basis of oral cancer - A case report \& literature review. J Oral Med, Oral Surg, Oral Pathol, Oral Radiol 2019;5(3):93-5. 